\title{
Estimating unrecorded human-caused mortalities of grizzly bears in the Flathead Valley, British Columbia, Canada
}

\author{
Bruce N. McLellan ${ }^{\text {Corresp., }}{ }^{1}$, Garth Mowat ${ }^{2,3}$, Clayton T. Lamb ${ }^{4}$ \\ 1 BC Ministry of Forests, Lands and Natural Resource Operations and Rural Development, D'Arcy, British Columbia, Canada \\ 2 Forest Sciences, BC Ministry of Forests, Lands and Natural Resource Operations and Rural Development, Nelson, British Columbia, Canada \\ 3 Department of Earth and Environmental Sciences, University of BC-Okanagan, Kelowna, British Columbia, Canada \\ 4 Department of Biological Sciences, University of Alberta, Edmonton, Alberta, Canada \\ Corresponding Author: Bruce N. McLellan \\ Email address: brucenmclellan@gmail.com
}

Managing the number of grizzly bear (Ursus arctos) mortalities to a sustainable level is fundamental to bear conservation. All known grizzly bear deaths are recorded by management agencies but the number of human-caused grizzly bear deaths that are not recorded is generally unknown, causing considerable uncertainty in the total number of mortalities. Here we compare the number of bears killed legally by hunters to the number killed by people for all other reasons, for bears wearing functioning radiocollars and for uncollared bears recorded in the British Columbia government mortality database for the Flathead Valley in southeast BC. Between 1980 and 2016, permitted hunters killed 10 collared bears and 12 ( 9 known, 3 suspected) were killed by people for other reasons. This ratio differed $(p<0.0001)$ from the uncollared bears in the government database where 71 were killed by hunters while only 10 were killed for other reasons. We estimate that $88 \%$ (95\% Cl; $67 \%-96 \%$ ) of the human-caused mortalities that were not by permitted hunters were unreported. The study area may have low reporting rates because it is $>40$ $\mathrm{km}$ on a gravel road from a Conservation Officer office, so reporting is difficult and there are no human residences so there is little concern of a neighbor contacting an officer. Our results are likely indicative of other places that are road-accessed but far from settlements. We discuss the implications of sampling individuals for collaring and the possible implications of wearing a collar on the animal's fate. 
130 August 2018

Bruce N. McLellan

BC Ministry of Forests, Lands and Natural Resource Operations and Rural Development

P.O. Box 1732,

D'Arcy B.C. V0N 1L0

Phone 604/452-3233;

bruce.mclellan@gov.bc.ca

RH: McLellan • Unrecorded Grizzly Bear Mortalities

Estimating Unrecorded Human-Caused Mortalities of Grizzly Bears in the Flathead Valley, British Columbia, Canada

Bruce N. McLellan ${ }^{1}$, Garth Mowat ${ }^{2,3}$, and Clayton T. Lamb ${ }^{4}$

${ }^{1}$ BC Ministry of Forests, Lands and Natural Resource Operations and Rural Development, P.O.

Box 1732, D’Arcy B.C. VON 1L0, Canada

${ }^{2}$ BC Ministry of Forests, Lands and Natural Resource Operations and Rural Development, Nelson, B.C. Canada

${ }^{3}$ Department of Earth, Environmental and Geographic Sciences, University of BC-Okanagan, Kelowna, B.C. Canada

${ }^{4}$ Department of Biological Sciences, University of Alberta, Edmonton, Alberta, Canada

\section{Abstract}

3 Managing the number of grizzly bear (Ursus arctos) mortalities to a sustainable level is

4 fundamental to bear conservation. All known grizzly bear deaths are recorded by management

5 agencies but the number of human-caused grizzly bear deaths that are not recorded is generally

6 unknown, causing considerable uncertainty in the total number of mortalities. Here we compare

7 the number of bears killed legally by hunters to the number killed by people for all other reasons,

8 for bears wearing functioning radiocollars and for uncollared bears recorded in the British

9 Columbia government mortality database for the Flathead Valley in southeast BC. Between 
101980 and 2016, permitted hunters killed 10 collared bears and 12 (9 known, 3 suspected) were

11 killed by people for other reasons. This ratio differed $(p<0.0001)$ from the uncollared bears in

12 the government database where 71 were killed by hunters while only 10 were killed for other

13 reasons. We estimate that $88 \%(95 \% \mathrm{CI} ; 67 \%-96 \%)$ of the human-caused mortalities that were

14 not by permitted hunters were unreported. The study area may have low reporting rates because

15 it is $>40 \mathrm{~km}$ on a gravel road from a Conservation Officer office, so reporting is difficult and

16 there are no human residences so there is little concern of a neighbor contacting an officer. Our

17 results are likely indicative of other places that are road-accessed but far from settlements. We

18 discuss the implications of sampling individuals for collaring and the possible implications of

19 wearing a collar on the animal's fate.

\section{Introduction}

21 Knowing how and why large mammals die is fundamental for effective management,

22 conservation, and even developing land-use policies. Documenting cause of death, however, is

23 often difficult. Some causes, such as legal hunting or the removal of conflict animals by agency

24 personnel can easily and accurately be quantified, while other causes, such as natural deaths or

25 vehicle/train collisions, may rarely be known without a sample of radiocollared individuals.

26 Documenting illegal killing can be much more difficult even with radiocollared animals. Some

27 people that illegally kill animals destroy radiocollars so animals being monitored seem to just

28 disappear (McLellan et al. 1999, Goodrich et al. 2008). For radiocollared animals, these events

29 have recently been called cryptic killing (Liberg et al. 2012). Although difficult to quantify,

30 various forms of unreported killing may be the dominant cause of death of animals in some areas

31 (McLellan et al. 1999, Chapron et al. 2008, Libieg et al. 2012, Sönnichsen et al. 2017, Treves et 32 al. 2017). 
34 large mammals, bears (Ursus spp.) have unique characteristics that make unreported humancaused mortality common. Unlike most other large mammals, bears are readily attracted to

36 human residences and temporary camps by a variety of food sources where they are sometimes

37 shot and their deaths are not always reported (McLellan et al. 1999). Grizzly bears (U. arctos), 38 particularly mothers with cubs, can be threatening to people so are sometimes shot in perceived 39 self-defense and such cases may also not be reported (McLellan et al. 1999, Garshelis et al. 2005, 40 Mace et al. 2012). Furthermore, bears are poached for body parts in some areas (Mills and 41 Servheen 1994).

Although there is considerable uncertainty over their eventual fates, an effort to limit human-caused mortality within sustainable limits has been the cornerstone of grizzly bear (Ursus arctos) conservation and management across much of their distribution (McLellan 1998,

Servheen 1998, Garshelis et al. 2005, Schwartz et al. 2010). All agencies in North America that manage grizzly bears maintain a database of bear mortalities dating back many decades. These data are used to direct management actions to most effectively reduce human-caused mortalities, keep the number of deaths below levels that may pose a conservation risk, as well as to estimate the number of bears that could be sustainably killed by hunters (McLellan et al. 2017). The number of unreported human-caused mortalities is unknown but evidence suggests that many deaths are not reported (McLellan et al. 1999, Cherry et al. 2002, Ciarniello et al. 2009, Lamb et al. 2017).

Here we estimate the proportion and number of human-caused grizzly bear deaths in the British Columbia (BC) Flathead Valley that were not in the government database by comparing the cause of death of a radiocollared sample of bears to the cause of death of bears that were not 
56 radiocollared in the government database. In BC, both radiocollared and uncollared bears were

57 legally killed by permitted hunters each year (McLellan et al. 2017). By law, parts of all hunted

58 bears had to be brought into an agency office for inspection where the deaths were recorded.

59 Due to this Compulsory Inspection regulation, we assume all permitted hunter-killed collared

60 and uncollared bears in the BC Flathead Valley were recorded in the government database.

61 Bears that were killed by people for other reasons and reported were also recorded in the

62 government database, but a number of human-caused mortalities are suspected to remain

63 unreported. The difference in the ratio of bears killed by permitted hunters to bears killed by

64 people for other reasons between the uncollared bears in the government database and the

65 radiocollared sample provides an estimate of the number of unrecorded human-caused

66 mortalities of uncollared bears. This method does not require a subjective estimate of whether or

67 not the death would have been recorded by the agency based on the circumstances of each case,

68 as done by McLellan et al. (1999). Nor does this method assume that the public will report

69 deaths of radiocollared and uncollared bears with equal probability or that reporting rates are

70 equal for all causes of mortality (Cherry et al. 2002).

71 Study area

The North Fork of the Flathead River begins in BC, Canada, and flows southward where

it crosses into Montana, USA, at $\mathrm{N} 49^{\circ}$ and $\mathrm{W} 114.48^{\circ}$ at an elevation of $1165 \mathrm{~m}$. The BC

74 Flathead is $1,585 \mathrm{~km}^{2}$ and is BC Wildlife Management Unit (MU) 4-01. The valley is about 12

$75 \mathrm{~km}$ wide at the border and ranges of the Rocky Mountains rise to 3,000 $\mathrm{m}$ on the east and 2,200

$76 \mathrm{~m}$ on the west. The valley in $\mathrm{BC}$ has been heavily logged. There has also been exploration for

77 gas, coal, and minerals but no extraction. In 2016, there were no paved roads but $1851 \mathrm{~km}$ of

78 gravel/dirt roads in MU-4-01 for an average density of $1.17 \mathrm{~km} / \mathrm{km}^{2}$, although some of these 
79 were closed seasonally to the public or annually to hunters. Lower elevations were dominated by

80 regenerating clearcuts and logging roads among some natural forests of lodgepole pine, western

81 larch (Larix occidentalis), and Douglas fir (Pseudotsuga menziesii). Higher elevations were also

82 dominated by regenerating cutblocks, but also Engelmann spruce (Picea engelmannii)-subalpine

83 fir (Abies lasiocarpa) forests, slowly regenerating historical burns, avalanche chutes, rock, talus,

84 and scree.

There were no permanent residents in the valley except 3 cabins within $1 \mathrm{~km}$ of the US border were occupied in the 1980s. The nearest highway and human settlement is about $40 \mathrm{~km}$ by gravel forestry road to the closest edge of MU 4-01 and >100 km to the far corners. The BC hunter survey suggests that an average of 2.6 hunter days per $\mathrm{km}^{2}$ were spent in pursuit of ungulates in MU 4-01 each autumn. Although some other MUs in BC where grizzly bears are hunted have almost 4 times the density of ungulate hunters, MU 4-01 has a higher ungulate

91 hunter density than $83 \%$ of the MUs in BC where grizzly bears are hunted. Due to the distance

92 from town, almost all hunting was based out of temporary camps with people staying mostly in

93 wall tents, small trailers, slide-in campers, and a few cabins. The area has few summer or winter 94 recreationists. general open season in the spring and fall for black bears but grizzlies were only hunted in the 97 spring. There was a draw for a limited number of grizzly bear permits for residents of BC with 98 the average odds being 1 in 29.2 of getting a permit from 2007 to 2016 . Non-residents of BC 99 only hunted with a registered outfitter that had a quota, which can be less than one grizzly per 100 year for a geographic territory with exclusive guiding rights. 


\section{Methods}

102 We examined the causes of mortality of grizzly bears using 2 datasets from MU 4-01.

103 One was the monitoring histories and causes of death of radiocollared bears. The second was the

104 BC government Compulsory Inspection (CI) database of dead grizzly bears.

105 Radiocollared animals are not a truly random sample (Goodrich et al. 2008). To reduce

106 possible bias, we captured bears at different times of year and used different methods. During

107 both spring and fall we captured bears using both foot snares and culvert traps. We also darted

108 grizzly bears from a helicopter in spring and summer. Capture and handling methods were

109 approved by the BC Fish and Wildlife Branch. No grizzly bears were captured because of

110 conflicts with people. We attached radiocollars with a canvas connector that decomposed

111 allowing the collar to drop after a planned period that varied from $<1$ yr to $6 \mathrm{yr}$ depending on the

112 age and sex of the bear and thus ended a monitoring session for that individual. Most collars

113 (217 of 255) were small brown or black VHF collars and not easily seen. All collars contained a

114 movement sensor which indicated the collar was dropped or the bear had died. We collared all

115 female bears captured between 1979 and 2016 but we only put collars on a few males after 2003.

116 Methods of tracking bears have been described in detail in McLellan (2015).

117 To estimate the implications of unknown fates, or when we lost contact with a

118 radiocollared bear so it became a candidate for cryptic killing, we recorded the duration and fate

119 of each monitoring session, as suggested by Treves et al. (2017). These fates were either: 1.

120 dead bear; 2. rotted canvas so collar dropped off; 3. collar/battery failure but bear was detected

121 later; 4. on-going monitoring, or 5. unknown fate. For each unknown fate, we recorded: 1. if the

122 collar had stopped transmitting when the bear was hibernating or not, 2 . the length of time the

123 collar had been transmitting before it stopped and compared these to transmitting times before 
124 collar/battery failure of bears known to have survived monitoring sessions as well as theoretical

125 battery life of the collar, and 3. in what jurisdiction or how far from MU 4-01 the bear was living

126 when it was no longer located. Based on these factors, we determined the number of cryptic

127 killing cases of collared bears that may have happened in MU 4-01.

128 Since 1976, all successful grizzly bear hunters in BC have been required by law to bring

129 the skull and hide to an agency office where the location of kill and sex of the bear was recorded

130 in the CI database. Grizzly bears killed for other reasons also had their sex, age, location of kill,

131 and cause of death recorded in the same database. Bear deaths were categorized as permitted

132 hunter kill, legal animal control, illegal kill, road kill or rail kill.

133 We classified deaths of radiocollared grizzly bear the same as the BC database except

134 natural mortalities were also recorded. All collared bears killed by permitted hunters were

135 reported. For legal reasons, we reported the death or suspected deaths of all collared bears to

136 Conservation Officers so these deaths were also in the CI database provided the carcass was

137 found.

138 In this study we compared the cause of death of our sample of bears when they were in

139 MU 4-01 and wearing a functioning radio collar to the cause of death of uncollared bears in the

140 CI dataset for MU 4-01, excluding all natural deaths. In particular, we compared the proportion

141 of all human-caused mortalities of collared bears that were killed by permitted hunters to the

142 same proportion for the uncollared bears in the CI database. Under the assumption that the

143 radiocollared bears represented an unbiased sample of mortality and that all legal hunter kills

144 were recorded in the CI database as is required by law, then the ratio of collared bears killed by

145 permitted hunters to collared bears killed by people for all other reasons should be the same ratio

146 for uncollared bears in the CI database. Deviations from this ratio would reflect the unreported 
147 human caused mortality (Equations 1 and 2).

148

$$
\frac{N H C}{H C}=\frac{N H U c i+N H U u n r e p o r t e d}{H U c i}
$$

That reduces to:

$$
\text { NHUunreported }=\left(\frac{H U c i}{\frac{H C}{N H C}}\right)-N H U c i
$$

1.

where NHUunreported is the estimated number of non-hunting deaths of uncollared bears that were are not reported, $\mathrm{HUci}$ is the number of permitted hunting kills of uncollared bears in the CI database, $H C$ is the permitted hunting deaths of collared bears, NHC is the number of nonhunting deaths of collared bears, and NHUci is non-hunting deaths of uncollared bears in the CI database. Comparing the estimated number of unreported kills to the number of reported kills that were not by permitted hunters in the CI database provides the proportion of these kills that were unreported.

We used 10,000 randomizations with replacement of both the collared and uncollared sample simultaneously using the Microsoft Excel (Microsoft, Redmond WA) add-in program PopTools (Hood 2011) to: 1. estimate the probability that the ratio of the kill by permitted hunters to bears killed by people for all other reasons was the same for the collared and uncollared sample, and 2 . estimate $95 \%$ confidence limits around the number and proportion of the non- permitted kill of uncollared grizzly bears that were not reported.

\section{Results}

In BC MU 4-01, 69 female grizzly bears were monitored for a total of 275 bear-years in 108 monitoring sessions (this includes recollaring of previously captured animals). Of these sessions 102 (94\%) had known fates. Of the 6 unknown fates, 4 had collars outlast expected battery life, and 1 collar approaching the expected battery life failed while the bear was hibernating, leaving only 1 whose collar stopped transmitting with 1.8 years of theoretical 
170 battery life remaining so was a candidate for cryptic killing. Because 15 of 36 bears had collars

171 stop transmitting in even less time but they were known to have survived the monitoring session,

172 and this individual lived in the most remote portion of MU 4-01, we suspect her collar just failed

173 prematurely, leaving no females with suspicious unknown fates.

174 In 81 monitoring sessions of 63 male grizzly bears covering 85 bear-years, 63 (78\%)

175 sessions ended with known fates. Of the 18 sessions with unknown fates, 11 ended with the bears

176 dispersing to or otherwise living in either Montana or Alberta so were unlikely to have been

177 cryptically killed in MU 4-01. Two collars stopped working when the bears were hibernating so

178 they would not have been killed by people at that time. Four sessions ended with suspected

179 cryptic killing; 2 in MU 01 and 2 in Montana (and thus not included in our analyses). In these

180 cases, the radiocollars stopped functioning prematurely when the bears, which were known to

181 have little fear of people, were located close to hunting camps in BC or residences in Montana.

182 In one case in $\mathrm{BC}$, a blood trail at the hunting camp was detected but neither the carcass or collar

183 were found. The final unknown fate was of a 3-year-old male that lived in both $\mathrm{BC}$ and

184 Montana. This bear could either have been cryptically killed, dispersed as young males often do

185 (McLellan and Hovey 2001), or the radiocollar could have failed prematurely; 9 of 36 collars on

186 males that were known to have survived their monitoring session stopped working in less time.

187 Between 1979 and 2016, 14 female grizzly bears died in MU 4-01 while wearing a

188 functioning radio collar (Table 1). Four were natural deaths, 4 were legally killed by grizzly bear

189 hunters, 3 were killed in defense of life or property by ungulate hunters, 1 was maliciously shot

190 and left on the roadside, and 1 was shot but we are unsure of the reason. Another female that

191 died we suspect had been shot by an ungulate hunter. If this female was killed by a person as we

192 suspect, then 4 of $10(40 \%)$ human-caused deaths of collared females were by permitted grizzly 
193 bear hunters; 4 of 9 (44\%) if this latter female died of natural causes.

194 Between 1979 and 2016, 11 males died with functioning collars in MU 4-01 (Table 1).

195 One was killed by another bear, 6 were legally killed by permitted hunters, 1 was shot at an

196 ungulate hunters' camp, 1 was killed in a neck snare set for wolves, and we are unsure why 2

197 were shot and left near the road side. In addition, were the 2 males suspected of being shot at

198 ungulate hunters' camps in MU 4-01. If these 2 males were cryptically killed as we suspect, then

1996 of $12(50 \%)$ human-caused deaths of collared males were by permitted grizzly bear hunters but

200 this would be 6 of $10(60 \%)$ if both of these males were not cryptically killed. When males and

201 female data are pooled, then permitted hunters would have killed 10 of 22 (45\%) of the collared

202 bears when the 3 suspected cases are included but 10 of $19(53 \%)$ if excluded.

203 The ratio between the number of permitted hunter kills to the number of human-caused

204 mortalities but for other reasons is much different for the uncollared bears in the CI database than

205 it was for the collared sample $(p<0.0001)$. In the CI database for MU 4-01, 26 of $28(93 \%)$ of

206 the uncollared females and 45 of 53 (85\%) uncollared males were killed by permitted grizzly

207 bear hunters or $88 \%$ when both sexes are pooled (Table 1). If uncollared bears were killed for

208 the same reasons as the collared sample and the 3 suspected cases are excluded, then $84 \%(95 \%$

209 CI; 51\%-95\%) of the deaths of uncollared bears by people without grizzly bear hunting permits

210 would have been unreported. If 3 suspected deaths of radiocollared bears are included, then $88 \%$

211 (95\% CI; 67\%-96\%) of these human-caused deaths would have been unreported. These rates

212 suggest that in addition to the 10 bears $(95 \% \mathrm{CI}, 5-16)$ in the CI database that were not killed by

213 permitted hunters, another 54 (95\% CI, 13-130) if suspected deaths of collared bears are

214 excluded or 75 (95\% CI, 26-197) if suspected deaths of collared bears are included, would have

215 also been killed but not reported. 


\section{Discussion}

217 Based on the circumstances of death of each radiocollared individual, McLellan et al.

218 (1999) estimated that 53\% of the 57 known or suspected non-hunting human-caused mortalities

219 of radiocollared bears would have been unknown to the management agency when data from 13

220 study areas were pooled. Of the 4 projects in BC, McLellan et al. (1999) estimated that 8 of 13

$221(62 \%)$ non-hunting mortalities would have been unknown to the management agency if the bears

222 had not been radiocollared. Some of these case by case subjective estimates of whether or not

223 the death would have been reported were likely incorrect; uncollared bears killed for non-hunting

224 reasons appear more unlikely to be reported than estimated by McLellan et al. (1999).

225 By comparing the ratio of bears killed by permitted hunters to those killed by people for

226 other reasons between the radiocollared bears and the uncollared bears in the CI database, our

227 estimates suggest that 84 to $88 \%$ of the bears killed by people for reasons other than permitted

228 hunting were not reported in the Flathead study area. In another heavily logged and well

229 accessed area in central BC, Ciarniello et al. (2009) had 3 collared bears killed legally by

230 permitted hunters and 5 killed for non-hunting reasons while in the CI database, when legally

231 killed conflict animals near human residences are excluded, 34 were legally shot by hunters and

232 only 5 were killed by people without hunting permits. Although sample sizes were very small,

233 these data also suggest that about $90 \%$ of bears killed by people for reasons other than permitted

234 hunting were not reported.

235 The reporting rate for non-hunting human-caused mortalities would be slightly lower if

236 the 2 bears in our study with unknown fates had been shot and their collars destroyed. We think

237 such a fate was unlikely in these cases. We did, however, include 2 cases of suspected cryptic

238 killing in our analysis. In these cases bears known to be habituated to human presence were last 
239 located near hunting camps and then their collars were never heard again.

240 Most non-hunting, human-caused grizzly bear mortalities were due to bears being

241 attracted to hunting camps or during threatening encounters with ungulate hunters in the field.

242 We suggest that there are features of the Flathead study area that makes reporting of non-hunter

243 killed grizzly bears uncommon. First, the entire drainage is $>40 \mathrm{~km}$ of gravel road from a

244 Conservation Officer office and there is no cellular phone service so reporting a kill is time

245 consuming and the chance of getting caught by a Conservation Officer for not reporting is

246 presumably less than closer to a town. Second, there are no residences so little concern of a

247 neighbor contacting an officer. In addition to the low reporting rate, the study area likely has a

248 relatively high proportion of non-hunter kills because almost all ungulate hunters are based in

249 field camps where grizzly bears are common as opposed to returning to their permanent

250 residence after hunting.

251 Like most studies of grizzly bear mortality rates and causes (Knight and Eberhardt 1985,

252 McLellan 1989, 2015, Mace et al. 2012, Garshelis et al. 2005, Schwartz et al 2006, Ciarniello et

253 al. 2009) as well as for other species, we assume our collared sample reflects the uncollared

254 population. Although a radiocollared sample may be the best available approximation (Goodrich

255 et al. 2008), it may not be an unbiased sample (McLellan et al. 1999, Schmidt et al. 2015,

256 Sönnichsen 2017, Treves et al. 2017). Biases can arise from two sources; which animals are

257 collared and if wearing a collar effects the probability that the animal will be killed. By catching

258 bears using foot snares and culvert traps during spring and fall plus darting from a helicopter

259 during spring and summer, we likely reduced any bias of sampling a disproportionate number of

260 bold or careless individuals that may be more likely to be killed by people than more cautious

261 bears. By limiting our analysis to MU 4-01, we also reduced the common tendency of collaring 
262 animals in less developed areas where densities (and survival) are higher than in more human-

263 dominated landscapes (McLellan et al. 1999, Schmidt et al. 2015, Treves et al 2017). Our focal

264 area is relatively homogeneous regarding access and in particular, there are no settlements or

265 paved roads. Although reducing bias, this restriction limits extrapolation. Reporting rates of

266 grizzly bears killed for non-hunting causes may be different in unroaded wilderness or in areas

267 with more human settlement and additional causes of mortality such as conflicts at residences

268 and road or railway strikes.

269 Finally, we assume that wearing a collar had no effect on whether or not a person would

270 kill a bear. If permitted bear hunters were more likely to refrain from shooting a bear because it

271 wore a collar than were poachers, or ungulate hunters that either had a bear attracted to their

272 camp or felt threatened by a bear, then our estimated reporting rate for non-hunter mortalities

273 would be biased high. If poachers or ungulate hunters were more likely to refrain from shooting

274 a bear because it wore a collar than were permitted bear hunters, then the reporting rate for non-

275 hunting mortalities would have been even lower. For several reasons, this potential bias is likely

276 less for grizzly bears in our study than for most other species. First, we almost exclusively used

277 small, dark VHF collars that were relatively difficult to see against the dark, dense fur on a

278 bear's neck compared to studies using larger and more obvious GPS collars or on species with

279 shorter neck hair. Second, grizzly bears usually live alone and therefore a hunter or poacher

280 cannot simply select the uncollared individual or individuals in a group to shoot. Third, unlike

281 most species, grizzly bears can be threatening and in such cases, a collar is unlikely to stop

282 someone from shooting a bear in a hunting camp or in perceived self-defense. Finally, shooting

283 a collared bear is legal and resident hunters had a 1 in 29 chance of drawing a permit and non-

284 residents had paid an outfitter (plus other costs) so hunters were unlikely to refrain from shooting 
285 a bear that they were interested in just because it wore a collar.

286 Having such a high number of unreported, non-hunting human-caused mortalities in

287 addition to the hunter kill is of concern for conservation. There is little doubt that the total

288 human-caused mortality in this area has affected a variety of population processes. Fortunately,

289 the procedure used in $\mathrm{BC}$ to calculate the number of bears that can be sustainably killed by all

290 causes used a model to predict the unreported human-caused mortality for all population units

291 (McLellan et al. 2017). For the Flathead, this model predicted a 2\% annual unrecorded human-

292 caused mortality rate which adequately compensated for this largely unknown factor.

293 Additionally, the study area is productive and high densities of grizzly bears remain and are

294 regulated by density-independent variability in food sources (huckleberry production) that

295 affected reproduction more than by human-caused mortality (McLellan 2015).

296 Conclusions

297

In the Canadian portion of the Flathead Valley, about $88 \%$ (95\% CI; 67\%-96\%) of the

298

uncollared grizzly bears that were killed by people for non-hunting causes were not recorded in

299 the government mortality database. Managers and researchers should know that most bears

300 killed by people for non-hunting reasons are unlikely recorded, at least in back-country areas.

301 Reporting rates may be higher in areas nearer to human settlement. This lack of reporting will

302 not only affect estimates of the total number of bears people kill but most other inferences

303 regarding human-caused mortalities that rely on government databases. A low reporting rate of

304 non-hunting human-caused mortalities may also be true for many species and this likelihood

305 should be considered.

306 Our method to estimate the reporting rate of human-caused mortalities relies on an

307 assumed $100 \%$ reporting of hunter killed bears. Where grizzly bears are not hunted, other forms 
308 of human-caused mortality with 100\% reporting, such as bears killed by conservation officers in

309 conflict situations, could be used as the known sample instead of hunter-killed bears to estimate

310 reporting rates of other forms of human-caused mortality.

\section{Literature cited}

312 Ciarniello, L. M., M. S. Boyce, D. R. Seip, and D. C. Heard. 2009. Comparison of grizzly bear

313 Ursus arctos demographics in wilderness mountains versus a plateau with resource

314 development. Wildlife Biology 15:247-265.

315 Chapron, G., D. G. Miquelle, A. Lambert, J. M. Goodrich, S. Legendre, and J. Clobert. 2008.

316 The impact on tigers of poaching versus prey depletion. Journal of Applied Ecology

$317 \quad 45: 1667-1674$.

318 Cherry, S., M. A. Haroldson, J. Robison-Cox, and C. C. Schwartz. 2002. Estimating total human-

319 caused mortality from reported mortality using data from radio-instrumented grizzly

$320 \quad$ bears. Ursus 13:175-184.

321 Garshelis, D. L., M. L. Gibeau, and S. Herrero. 2005. Grizzly bear demographics in and around Banff National Park and Kananaskis Country, Alberta. Journal of Wildlife Management

324 Goodrich, J. M., L. L. Kerley, E. N. Smirnov, D. G. Miquelle, L. McDonald, H. Quigley, M. G. Hornocker, and T. McDonald. 2008. Survival rates and causes of mortality of Amur tigers on and near the Sikhote-Alin Biosphere Zapovednik. Journal of Zoology (London) $276: 323-329$.

328 Hood, G. M. 2011. Poptools Version 3.2.5. www.poptools.org. Accessed August 31, 2017.

329 Knight, R. R., and L. L. Eberhardt. 1985. Population dynamics of Yellowstone grizzly bears.

$330 \quad$ Ecology 66:323-334. 
331 Lamb, C. T., G. Mowat, B. N. McLellan, S. E. Nielsen, S. Boutin. 2017. Forbidden fruit: human

332

333

334

335

336

337

338

339

340

341

342

343

344

345

346

347

348

349

350

351

352

353

settlement and abundant fruit create an ecological trap for an apex omnivore Journal of Animal Ecology 86:55-65

Liberg, O., G. Chapron, P. Wabakken, H. C. Pedersen, N. T. Hobbs, and H. Sand. 2012. Shoot, shovel and shut up: cryptic poaching slows restoration of a large carnivore in Europe. Proceedings of the Royal Society of London, B. Biological Sciences 270:91-98.

Mace, R. D., D. W. Carney, T. Chilton-Radant, S. A. Courville, M. A. Haroldson, R. B. Harris, J. Jonkel, B. N. McLellan, M. Madel, R. L. Manley, C. C. Schwartz, C. Servheen, G. Stenhouse, J. S. Waller, and E. Wenum. 2012. Grizzly bear population vital rates and trend in the Northern Continental Divide Ecosystem, Montana. Journal of Wildlife Management 76:119-128.

McLellan, B. N. 1989. Population dynamics of grizzly bears during a period of resource extraction development. II. Mortality rates and cause of death. Canadian Journal of Zoology 67:1861-1864.

McLellan, B. N. 1998. Maintaining viability of brown bears along the southern fringe of their distribution. Ursus 10: 607-611.

McLellan, B. N. 2015. Some mechanisms underlying variation in vital rates of grizzly bears on a multiple-use landscape. The Journal of Wildlife Management 79:749-765

McLellan, B. N., and F. W. Hovey. 2001. Natal dispersal of grizzly bears. Canadian Journal of Zoology. 79:838-844

McLellan, B. N., F. Hovey, J. Woods, M. Gibeau, D. Carney, R. Mace, W. Wakkinen, and W. Kasworm. 1999. Rates and causes of grizzly bear mortality in the interior mountains of British Columbia, Alberta, Montana, and Idaho. Journal of Wildlife Management 
63:911-920.

355

356

357

358

359

360

361

362

363

364

365

366

367

368

369

370

371

372

373

374

375

McLellan, B. N., G. Mowat, T. Hamilton, and I. Hatter. 2017. Sustainability of the grizzly bear hunt in British Columbia, Canada. Journal of Wildlife Management. 81:218-229

Mills, J. and C. Servheen. 1994. The Asian trade in bears and bear parts: impacts and conservation recommendations. Bears, their biology and management 9:161-167.

Schmidt, J. H., D. S. Johnson, M. S. Lindberg, and L. G. Adams. 2015. Estimating demographic parameters using a combination of known-fate and open N-mixture models. Ecology $56: 2583-2589$.

Schwartz, C. C., M. A. Haroldson, and G. C. White. 2010. Hazards affecting grizzly bear survival in the greater Yellowstone ecosystem. Journal of Wildlife Management 74:654667.

Schwartz, C. C., M. A. Haroldson, G. C. White, S. Cherry, K. A. Keating, D. Moody, and C. Servheen. 2006. Temporal, spatial, and environmental influences on the demographics of grizzly bears in the greater Yellowstone Ecosystem. Wildlife Monographs 161:1-68.

Servheen, C. 1998. The grizzly bear recovery program: current status and future considerations: Ursus 10: 591-596

Sönnichsen, L., T. Borowik1, T Podgórski1, K. Plis, A. Berger, and B. Jędrzejewska1. 2017. Survival rates and causes of mortality of roe deer Capreolus capreolus in a rural landscape, eastern Poland. Mammal Research 62:141-147

Treves A., K. A. Artelle, C. T. Darimont, and D. Parsons D. 2017. Mismeasured mortality: correcting estimates of wolf poaching in the United States. Journal of Mammalogy 98: $1256-1264$ 


\section{Table $\mathbf{1}$ (on next page)}

The number of radio collared and uncollared grizzly bears that were known to have died (suspected in parentheses) in the Flathead Valley of British Columbia, 1979 to 2016. 


\begin{tabular}{llcc}
\hline Sex & Cause of Death & Collared & Uncollared in CI database \\
\hline Male & Natural & 1 & 0 \\
& Legal Hunting & 6 & 45 \\
& Nonhunting & $4(2)$ & 8 \\
Females & Natural & 4 & 0 \\
& Legal Hunting & 4 & 26 \\
& Nonhunting & $5(1)$ & 2 \\
Both & Natural & 5 & 0 \\
& Legal Hunting & 10 & 71 \\
& Nonhunting & $9(3)$ & 10 \\
\hline
\end{tabular}

1 